\title{
Influence of parameters in soil hardening model on deformation of excavation
}

\author{
Peng-fei $\mathrm{CHEN}^{1 \mathrm{a}^{*}}$, Xiao-nan $\mathrm{GONG}^{1}$ \\ ${ }^{1}$ Research Center of Coastal and Urban Geotechnical Engineering, Zhejiang University, Hangzhou, China
}

\begin{abstract}
Based on the data of the soil and enclosure structure of a certain excavation, a PLAXIS model was established. The actual monitoring results are compared with the PLAXIS calculation results to verify the reliability of the model. On this basis, the six main parameters in the soil hardening model were changed by a single variable method to obtain the influence of each parameter on the deformation of the excavation. As the soil weight or Poisson's ratio increases, the lateral displacement of the retaining wall increases. With the increase of the secant modulus or cohesive force or internal friction angle of the soil, the lateral displacement of the retaining wall decreases. The power index $\mathrm{m}$ has basically no effect on the lateral displacement of the retaining wall. With the increase of $\mathrm{m}$, the settlement of the soil gradually increases uniformly.
\end{abstract}

\section{Introduction}

In the analysis of the deformation and force of excavation, the soil hardening model (HS) is a common choice ${ }^{1}$. However, since some parameters in the model will not be provided in the geotechnical survey report, the usual method is to perform trial calculations based on previous research or engineering experience ${ }^{2}$. In this way, the calculation results often differ greatly from the actual situation in the calculation process. However, because there are many parameters for trial calculation, it is often impossible to confirm which parameter is not accurate enough to cause the wrong result. This paper studies the influence of the main parameters in the HS model on the deformation of the excavation, and analyzes the sensitivity of the deformation of the excavation to each parameter.

Liu Chang ${ }^{3}$ obtained some parameters of the soil hardening model in Tianjin area through experiments. Wang Weidong ${ }^{4}$ studied the relationship between the three deformation moduli in the HS model in Shanghai through experiments. Xu Zhonghua ${ }^{5}$ and others did research on the selection of soil constitutive model in the numerical analysis of excavation in sensitive environments. Chen Pengfei ${ }^{6}$ et al. studied the parameter values of the waterproof curtain mixing pile.

\section{Engineering background and model establishment}

The total land area of the project is about $5424 \mathrm{~m}^{2}$. The above ground construction area is about $18984 \mathrm{~m}^{2}$. The underground construction area is about $14542 \mathrm{~m}^{2}$. The proposed building adopts a frame shear wall structure. The foundation type uses bored piles. There are three basements with a safety level of level 1, and the buried depth of the basement is about 14.5 meters. The retaining structure of the excavation adopts diaphragm wall and concrete internal supports.

In the PLAXIS 3D model, the soil is $300 \mathrm{~m}$ long, $300 \mathrm{~m}$ wide, and $75 \mathrm{~m}$ deep. The hardening model is selected for the soil, and the average value of each parameter is taken. The weight $\gamma=19 \mathrm{kN} / \mathrm{m}^{3}$, the cohesion $c=20 \mathrm{kPa}$, the internal friction angle $\varphi=20^{\circ}$, and the three deformation moduli $E_{50}^{r e f}=10 M P a, E_{\text {oed }}^{r e f}=10 M P a$, $E_{\mathrm{ur}}^{r e f}=60 \mathrm{MPa}$, Poisson's ratio $v=0.25$. The excavation is $100 \mathrm{~m}$ long, $50 \mathrm{~m}$ wide and $15 \mathrm{~m}$ deep. The enclosure structure is an underground continuous wall (plate), the wall depth is $30 \mathrm{~m}$, the embedded depth is $15 \mathrm{~m}$, and the wall thickness is $0.8 \mathrm{~m}$. There are 3 layers of inner support, respectively at depths of $0 \mathrm{~m},-5 \mathrm{~m}$, and $-10 \mathrm{~m}$. The retaining wall and internal support are both concrete structures, with elastic modulus $E=30 G P a$ and Poisson's ratio $v=$ 0.15 .

Set this model as the reference model. The influence of various variables on the deformation of the excavation will be discussed below. All changes in a single variable are made on this reference model, and other parameters remain unchanged.

Based on the above data, the model was established. The deformation calculation results and measured data of the envelope structure are shown in the figure 1.

It can be seen from the figure 1 that the model calculation result is relatively close to the actual

${ }^{1}$ Corresponding author: 21212003@zju.edu.cn 
measurement result, and the maximum lateral displacement of the wall calculated by the model is slightly larger than the actual measurement value.

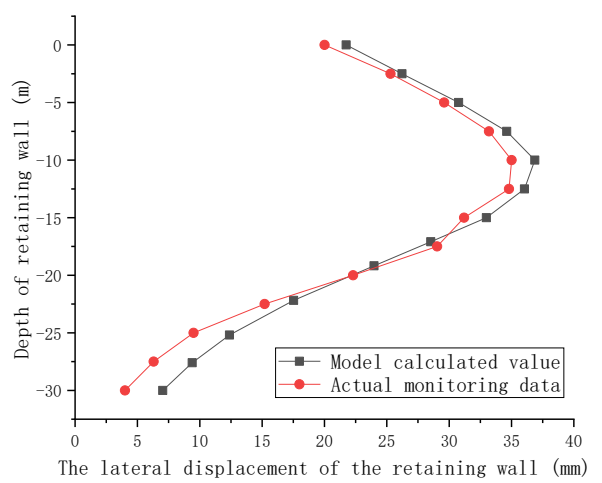

Fig. 1. Comparison of measured value and calculated value.

\section{Results and Discussion}

\subsection{The influence of soil gravity}

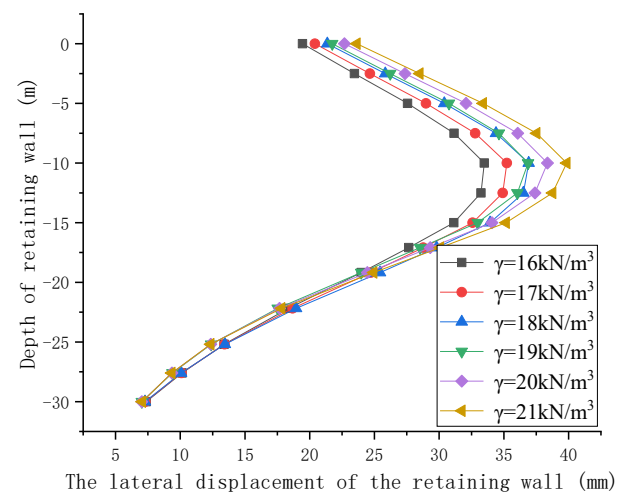

Fig. 2. The influence of soil weight on deformation.

The figure 2 is the relationship between the soil gravity and the lateral displacement of the retaining wall. When increasing from $\gamma=16 \mathrm{kN} / \mathrm{m}^{3}$ to $\gamma=21 \mathrm{kN} / \mathrm{m}^{3}$, the lateral displacement of the retaining wall gradually increases, from $33.5 \mathrm{~mm}$ to $39.8 \mathrm{~mm}$. Because the gravity stress of the soil is proportional to the gravity of the soil, and the lateral pressure of the soil is proportional to the gravity stress, the greater the $\gamma$, the greater the earth pressure acting on the retaining wall and the greater the deformation of the retaining wall.

We should also note that the influence of soil gravity on the deformation of the excavation is mainly above the excavation surface of the excavation ${ }^{7}$. There are two main reasons for this: First, it is related to the sequence of excavation. During the layered excavation process, the earth pressure outside the excavation first gradually acts on the retaining wall, and the deep soil in the pit often does not play its role until later. This sequence makes the impact of soil gravity on the deformation of the excavation mainly concentrated above the excavation surface. The second is related to the nature of the stress on the soil inside and outside the pit. The soil outside the pit is in a state of active earth pressure, which is a load, and its role is fully exerted. The soil in the pit is in a state of passive earth pressure, which belongs to resistance, and its function is released only when the load is required.

\subsection{The influence of the secant modulus}

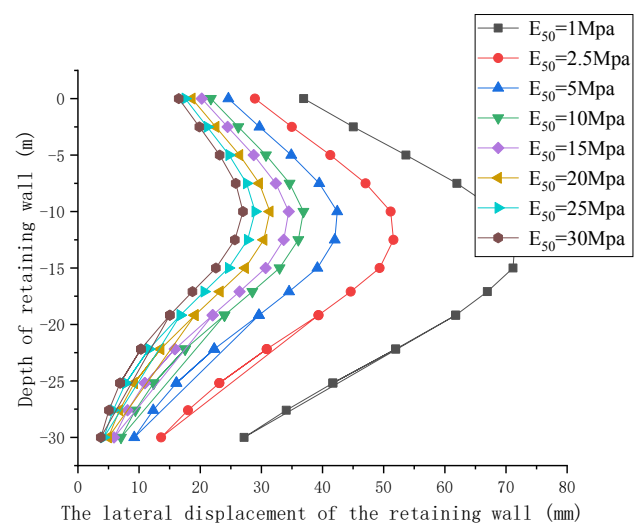

Fig. 3. The influence of secant modulus on deformation The figure 3 is the relationship between the lateral displacement of the retaining wall and the secant modulus of the soil. In the benchmark model of this paper, $E_{50}^{r e f}=$ $10 M P a$, it can be seen from the figure that when $E_{50}^{r e f}=$ $10 M P a$ is reduced to $E_{50}^{r e f}=1 M P a$, the lateral displacement has a very large increase, and the degree of increase is getting larger and larger, from $36.9 \mathrm{~mm}$ to $71.6 \mathrm{~mm}$, which is about doubled, beyond the allowable range. When $E_{50}^{r e f}=10 M P a$ increases to $E_{50}^{r e f}=$ $30 \mathrm{MPa}$, the lateral displacement is slowly reduced, from $36.9 \mathrm{~mm}$ to $27 \mathrm{~mm}$, approximately to the original $73 \%$. It should also be noted that with the decrease of $E_{50}^{r e f}$, the lateral displacement of the entire retaining wall, including the top and bottom of the wall, has increased, not just the increase in the maximum lateral displacement of the middle of the retaining wall. It tells that there is a risk of kicking damage.

\subsection{The influence of the cohesion}

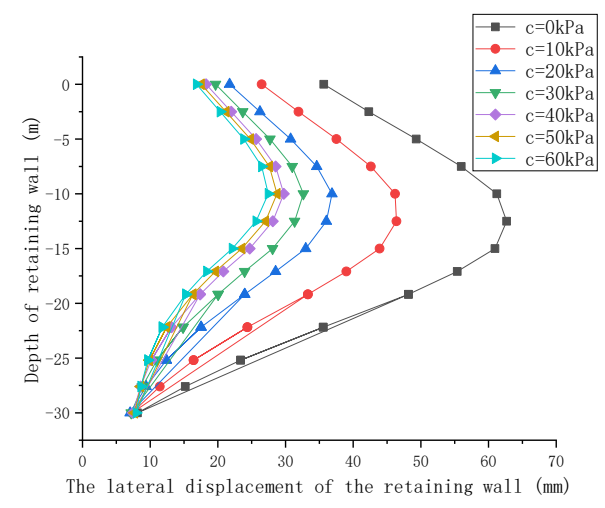

Fig. 4. The influence of cohesion on deformation 
The figure 4 is the relationship between the lateral displacement of the retaining wall and the cohesion $\mathrm{c}$ of the soil. In the benchmark model in this paper, $\mathrm{c}=20 \mathrm{kPa}$. It can be seen from the figure that when $c=20 \mathrm{kPa}$ decreases to $\mathrm{c}=0 \mathrm{kPa}$, the lateral displacement has a very large increase, and the degree of increase is getting bigger and bigger, from $36.9 \mathrm{~mm}$. to $62.8 \mathrm{~mm}$, an increase of about $70 \%$ which is beyond the allowable range. When $\mathrm{c}=20 \mathrm{kPa}$ increases to $\mathrm{c}=60 \mathrm{kPa}$, the lateral displacement gradually decreases, from $36.9 \mathrm{~mm}$ to $27.5 \mathrm{~mm}$, which is about $25 \%$ reduction.

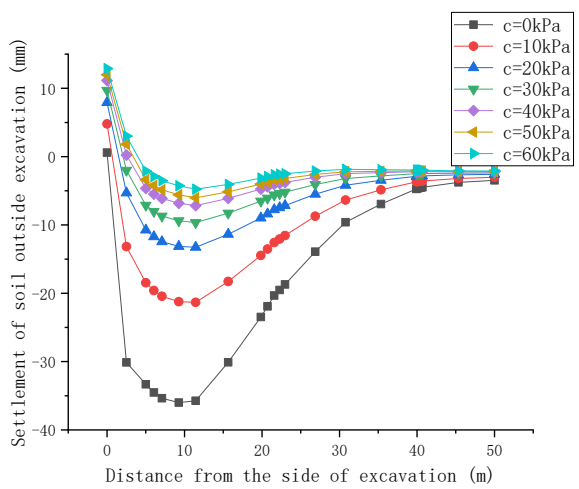

Fig. 5. The influence of cohesion on settlement

The figure 5 shows the relationship between the settlement outside the pit and the cohesion of the soil. In this paper's benchmark model $\mathrm{c}=20 \mathrm{kPa}$. It can be seen from the figure that when $\mathrm{c}=20 \mathrm{kPa}$ decreases to $\mathrm{c}=0 \mathrm{kPa}$, the settlement has a very large increase, and the degree of increase is getting bigger and bigger. It has increased from $13.4 \mathrm{~mm}$ to $42 \mathrm{~mm}$, which is approximately 2 times larger, which exceeds the allowed range of the specification. When $\mathrm{c}=20 \mathrm{kPa}$ increases to $\mathrm{c}=60 \mathrm{kPa}$, the settlement gradually decreases, from $13.4 \mathrm{~mm}$ to $5 \mathrm{~mm}$, which is about $37.3 \%$ of the original.

\subsection{The influence of the internal friction angle}

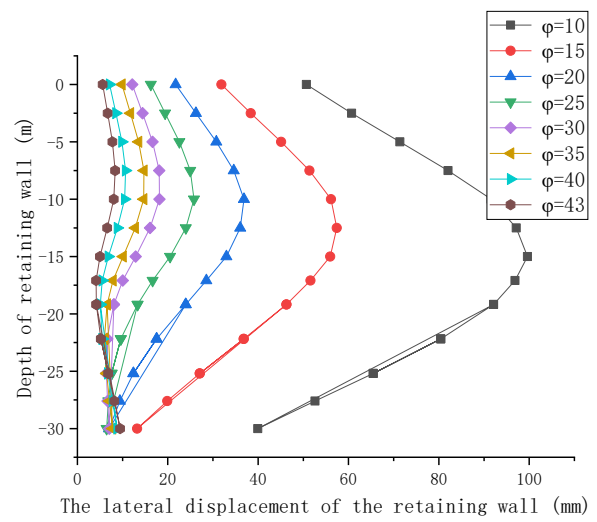

Fig. 6. The influence of internal friction angle on deformation The figure 6 is the relationship between the lateral displacement of the retaining wall and the internal friction angle of the soil. In the benchmark model of this paper, $\varphi=20^{\circ}$. It can be seen from the figure that when $\varphi=$ $20^{\circ}$ is reduced to $\varphi=10^{\circ}$, the lateral displacement has a very large increase, and the degree of increase is more and more large, increased from $36.9 \mathrm{~mm}$ to $99 \mathrm{~mm}$, an increase of about 1.68 times, far beyond the allowed range of the specification. When $\varphi=20^{\circ}$ increases to $\varphi=$ $43^{\circ}$, the lateral displacement gradually decreases, from $36.9 \mathrm{~mm}$ to $9.5 \mathrm{~mm}$, which is about $26 \%$ of the original. When $\varphi=43^{\circ}$, the shape of the deformation curve of the retaining wall has changed. The lateral displacement in the middle of the retaining wall is already smaller than the lateral displacement at the bottom of the wall.

When the internal friction angle $\varphi<20^{\circ}$ in geotechnical investigation and excavation design calculation, special attention should be paid to the accuracy of the value.

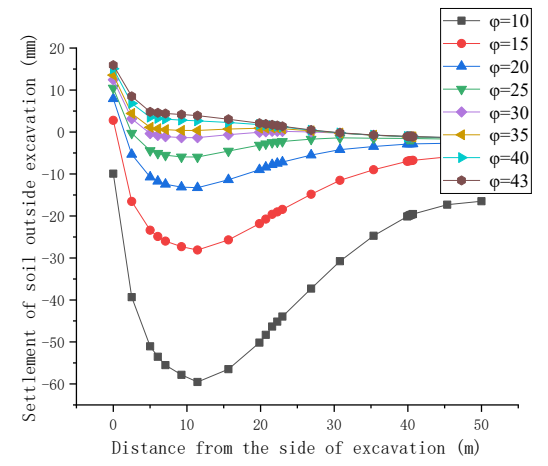

Fig. 7. The influence of internal friction angle on settlement The figure 7 is the relationship between the settlement outside the pit and the internal friction angle of the soil. In the benchmark model of this article $\varphi=20^{\circ}$. It can be seen from the figure that when $\varphi=20^{\circ}$ is reduced to $\varphi=10^{\circ}$, the settlement has a very large increase, and the degree of increase is getting larger. It increased from $13.4 \mathrm{~mm}$ to $126 \mathrm{~mm}$, an increase of approximately 8 times, far beyond the allowed range of the specification. When $\varphi=20^{\circ}$ increased to $\varphi=43^{\circ}$, the settlement gradually decreased.

\subsection{The influence of the Poisson's ratio}

The figure 8 is the relationship between the lateral displacement of the retaining wall and the Poisson's ratio of the soil. It can be seen from the figure that $v=0.35$ is the cutoff value. When increasing from $v=0.35$ to $v=$ 0.49 , the lateral displacement increases significantly, from $40 \mathrm{~mm}$ to $52 \mathrm{~mm}$, which is about $30 \%$ increase. When reducing from $v=0.35$ to $v=0.15$, the lateral displacement gradually decreases, from $40 \mathrm{~mm}$ to $36 \mathrm{~mm}$. It is reduced by about $10 \%$.

We should note that the influence of Poisson's ratio on the deformation of the excavation has obvious effects on the bottom of the retaining wall. However, it has a greater impact on the deformation below the bottom of the pit. It is found that the increase in Poisson's ratio makes a great change in the horizontal displacement of the bottom of the wall, which is much larger than the change in the horizontal displacement of the top of the wall. 


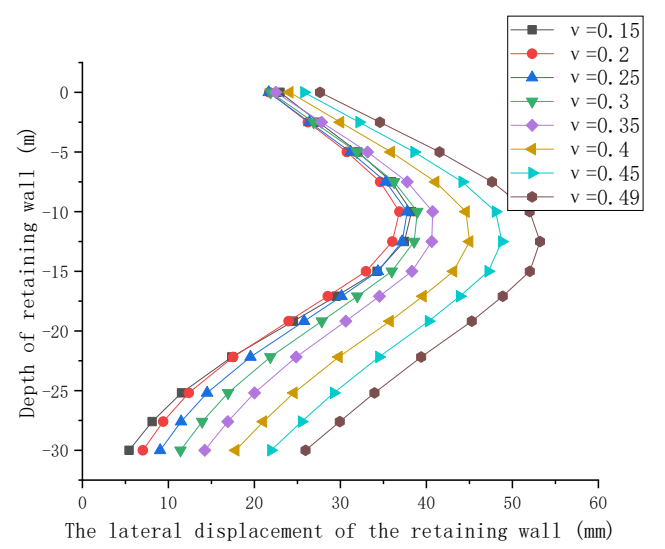

Fig. 8. The influence of Poisson's ratio on deformation

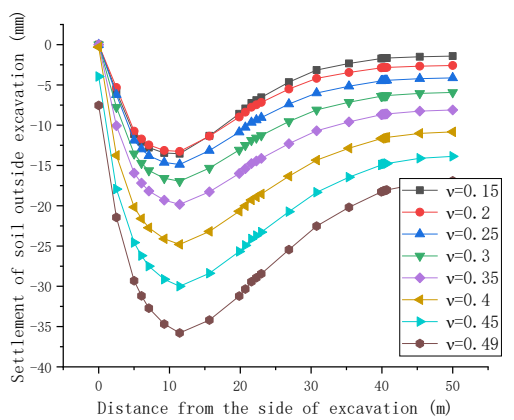

Fig. 9. The influence of Poisson's ratio on settlement The figure 9 is the relationship between soil settlement and Poisson's ratio. It can be seen from the figure that $v=$ 0.35 is the cut-off value. When increasing from $v=$ 0.35 to $v=0.49$, the settlement increases significantly from $29 \mathrm{~mm}$ to $60 \mathrm{~mm}$, which is about doubled. When reducing from $v=0.35$ to $v=0.15$, the settlement gradually decreases, from $29 \mathrm{~mm}$ to $13.4 \mathrm{~mm}$. It reduced by about $55 \%$.

\subsection{The influence of the power exponent $\mathrm{m}$}

It is calculated that the power exponent $m$ related to the modulus stress level has basically no effect on the lateral displacement of the retaining wall. Therefore, the image is not drawn.

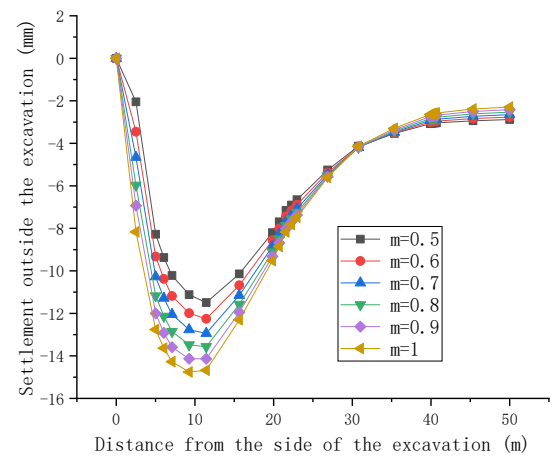

Fig. 10. The influence of $m$ on settlement
The figure 10 is the relationship between the settlement outside the pit and the power exponent. It can be seen that as $\mathrm{m}$ increases from 0.5 to 1 , the settlement of the soil gradually increases uniformly, from $12.1 \mathrm{~mm}$ to $14.76 \mathrm{~mm}$, an increase of about $20 \%$.

\section{Conclusion}

Through the establishment of the PLAXIS 3D model, the influence of the six main parameters in the HS soil model on the deformation of the excavation was studied, and the following conclusions were obtained:

As the soil weight or Poisson's ratio increases, the lateral displacement of the retaining wall increases.

With the increase of the secant modulus or cohesive force or internal friction angle of the soil, the lateral displacement of the retaining wall decreases.

The power index $\mathrm{m}$ has basically no effect on the lateral displacement of the retaining wall. With the increase of $\mathrm{m}$, the settlement of the soil gradually increases uniformly.

\section{References}

1. Liu, G.B., Wang, W.D. (2009) Excavation engineering handbook. China Architecture and Building Press, Beijing

2. Xu, Z.H., Wang, W.D. (2010) Selection of soil constitutive models for numerical analysis of deep excavations in close proximity to sensitive properties. Rock and Soil Mechanics, 31(1): 258264.

3. Liu, C. (2008) Analysis of deformation and stress due to deep excavation considering different deformation and strength parameters of soil and space effect of excavation and retaining structure. Tianjin University, Tianjin.

4. Wang, W.D., Wang H.R., Xu, Z.H. (2012) Experimental study of parameters of hardening soil model for numerical analysis of excavations of excavations. Rock and Soil Mechanics, 33(8): 2283-2290.

5. Xu, Z.H., Wang, J.H., Wang, W.D. (2006) Analysis of a complicated deep excavations supported by substructures. Chinese Journal of Geotechnical Engineering, 28(S1): 1355-1359.

6. Chen, P.F., Gong, X.N., Liu, N.W. (2014) Effect of curtain's role in retaining on deformation of deep excavations. Chinese Journal of Geotechnical Engineering, 36(11): 254-258.

7. Liu, G.B., Hou, X.Y. (1996) Unloading modulus of the Shanghai soft clay. Chinese Journal of Geotechnical Engineering, 18(6): 18-23. 